\title{
EM NOME DA SEGURANÇA NACIONAL: Os Escritores na Mira da Polícia
}

\section{ON BEHALF OF THE NATIONAL SECURITY: The Writers in the Aiming of the Policy}

Ana Paula Palamartchuk

\begin{abstract}
"Procurei em redor um daqueles temerosos carros, os tintureiros, marcados com um dístico, eufemismo extravagante: assistência policial. Jogam-nos ali, esmagam-nos, indiferentes à capacidade, e batem a porta; viajamos na treva e no calor, como bichos, atormentados pela desagradável assistência."

Graciliano Ramos, Memórias do cárcere (4o. Vol.), 1953.
\end{abstract}

\begin{abstract}
Resumo:
A existência de uma literatura "perigosa" é, em parte, criação da polícia política nos anos trinta. As trajetórias de Jorge Amado, Caio Prado Júnior e Dionélio Machado dimensionam aqui as relações entre política e literatura no processo de estruturação dos órgãos estatais de repressão e censura. A triangulação que se estabelece entre 0 escritor, sua produção intelectual e o seu posicionamento político tem a ver com a aquisição de um certo poder simbólico capaz de impor alguns limites às arbitrariedades da polícia política. Ao mesmo tempo em que essa mesma literatura passa a ser visada pela polícia como "perigosa", as relações sociais possíveis de serem estabelecidas pelos escritores, não num suposto mundo intelectual, mas sim nas experiências compartilhadas nas atividades político-literárias, possibilitam entender o processo de criação desta suposta "literatura comunista" e a sua criminalização.
\end{abstract}

Palavras-chave: História do Brasil República, Getúlio Vargas, Intelectuais, Cultura, Crime Político.

\begin{abstract}
:
The existence of a literature "dangerous" is partly the creation of the political police in the thirties. The trajectories of Jorge Amado, Caio Prado Júnior and Machado Dionálio here they measure the relationship between politics and literature in the process of structuring the state organs of repression and censorship. Triangulation established between the writer, his intellectual production and its political positioning has to do with the acquisition of a certain symbolic power able to impose some limits to the arbitrariness of the political police. At the same time this same literature is being targeted by police as "dangerous" social relations likely to be established by the writers, not a supposed intellectual world, but on shared experiences in political and literary activities, allow to understand the process creation of this supposed "communist literature" and its criminalization.
\end{abstract}

Keywords: History of the Republic of Brazil, Getúlio Vargas, Intellectuals, Culture, Political Crime.

Nos anos trinta, a constituição de novos movimentos sociais, o reflorescimento dos sindicatos, ainda que à custa da intervenção autoritária do Estado, setores profissionais, antes dispersos, que começavam a se organizar forçavam alguns parlamentares a garantirem direitos democráticos, muitas vezes cobrando posições do governo em relação à censura e prisões arbitrárias de trabalhadores, lideranças sindicais, escritores, jornalistas, advogados, professores, médicos, etc.

Esses novos "movimentos sociais"1 eram iniciativas que se avolumavam para responder

\footnotetext{
* Professora Adjunta do Curso de História da Universidade Federal de Alagoas. Doutora em História pela UNICAMP.

1 Para uma análise sobre as diversas interpretações sobre os "movimentos sociais" ver, sobretudo: Dagnino, Evelina. "Cultura, cidadania e democracia. A transformação dos discursos e práticas na esquerda latino-americana", in: _org.), Cultura e política nos movimentos sociais latino-americanos. Novas leituras. Belo Horizonte, Editora UFMG, 2000, pp. 61-102. Durham, Eunice Ribeiro. "Movimentos Sociais. A construção da cidadania", in: Novos Estudos Cebrap, São Paulo, outubro/1984, n. 10, pp. 24-30. Nenhum dos artigos se refere ao
} 
ao descontentamento gerado por medidas políticas, econômicas e sociais do governo de Getúlio Vargas e por ecos das tensões internacionais. A formação de organizações, que reuniram vários setores democráticos, liberais e populares da sociedade civil contra ameaças anti-democráticas endógenas, e contra uma nova guerra mundial e o fascismo que ganhava rapidamente novos adeptos, teve ampla repercussão.

Muitas destas organizações como, por exemplo, o Comitê Antifascista Brasileiro, Frente Única Antifascista, Comitê de Luta Contra a Guerra, contra o Fascismo e a Reação, Comitê Estudantil Antiguerreiro, Comitê Antifascista Italiano de São Paulo, Comitê Antifascista Lituano de São Paulo, Federação Operária de São Paulo, Legião Cívica 5 de Julho, Grêmio Universitário Socialista, União dos Trabalhadores Gráficos, Liga Comunista, Partido Socialista Italiano, Bandeira dos 18, Grupo Itália Libera, Centro de Resistência dos Trabalhadores de São Paulo, Liga Comunista, Partido Socialista Brasileiro, Partido Comunista do Brasil, passavam a ser "suspeitas" de atividade subversiva, sendo vigiadas e investigadas pela polícia política como demonstra um conjunto de relatórios produzidos nas delegacias e departamentos policiais. Essas "suspeitas" se baseavam no pressuposto de que esses movimentos eram organizados e liderados por comunistas e que suas ações tinham o objetivo de "subverter a ordem".

Os relatórios da polícia ajudam a reconhecer o que acontecia nas ruas e dentro dos gabinetes. A participações de investigadores da polícia nessas organizações tinha 0 evidente propósito de descrever as atividades e identificar seus participantes.

Em uma dessas ocasiões, em novembro de 1933, 150 pessoas se reuniram na sede da Classes Laboriosas, em São Paulo, para assistirem à Conferência Anti-integralista, dirigida por Aristides Lobo, membro da Liga Vermelha e da União dos Trabalhadores Gráficos (UTG). Com o fim da conferências, por volta das 23 horas, parte da assistência dirigiu-se à Praça da Sé, onde, a convite de Lobo, cantaram a Internacional Comunista. Como estavam apenas passando por ali, indo em direção ao Parque Dom Pedro e ao Brás, onde pegariam os bondes para casa, continuaram a caminhada. Já próximos ao Parque Dom Pedro, foram perseguidos por um grupo de policiais que diziam ter ordens de prisão. Em meio à confusão, uma arma foi disparada para 0 alto e o chefe da ação policial disparou várias vezes. Teve início um violento tiroteio com alguns feridos e a prisão de vários "comunistas e anarquistas"2.

Em nome da "ordem" e da "segurança nacional", a polícia justificou os mais arbitrários atos: proibir atividades em defesa da democracia, de reivindicações de melhores condições de vida, etc. Há dezenas de episódios desse tipo que envolveram várias organizações na luta pela democracia e, através deles, podemos perceber as relações entre a sociedade civil organizada e

período aqui tratado, mas impõem questões pertinentes ao caso estudado, como por exemplo: surgimento de movimentos sociais causado pela consciência das más condições sociais de vida ou pelas necessidades materiais que não são supridas?; quais relações entre o Estado e a formação de uma sociedade civil expressa na organização de movimentos populares?; a visão estadista da política não reforça a ideia de cultura apenas como instrumento de controle e dominação social?

2 Relatório Policial sobre a Conferência Anti-Integralista, 15 de novembro de 1933. Pront. n. 37 - Aristides Lobo, DEOPS-SP, AESP. 
as instituições de repressão e censura do estado que eram fortalecidas e legitimadas na mesma proporção em que o Estado-Nação se consolidava e construia o nacionalismo3.

Um recurso usado pelas organizações para se protegerem contra as arbitrariedades da polícia e tentar manter 0 estado de direito foi o envolvimento de muitos deputados e do parlamento no controle das atividades da polícia política. O deputado Mozart Lago, por exemplo, em agosto de 1934, pediu informações sobre a orientação da chefatura de polícia do Distrito Federal aos seus subordinados na execução do $\S 21^{\circ}$, do artigo 113 , da Constituição, onde se lia:

\begin{abstract}
"Ninguém será preso senão em flagrante delito, ou por ordem escrita da autoridade competente, nos casos expressos em lei. A prisão ou detenção de qualquer pessoa será imediatamente comunicada ao juiz competente, que relaxará se não for legal, e promoverá, sempre que de direito, a responsabilidade da autoridade coatora.[...]"4.
\end{abstract}

Müller respondeu ao MJNI que todas as instruções já haviam sido transmitidas aos seus subordinados. No entanto, o chefe de polícia não respondeu à acusação do deputado de que havia ilegalidade em muitas das ações policiais, nas quais o "réu" a priori era impossibilitado de fazer uso dos instrumentos da justiça.

As prisões individuais também demonstram as formas de ação policial em torno e "elementos suspeitos". Foi o caso de um dos membros do Comitê Central do PCB, Augusto Besouchet que havia desaparecido no final de 1934 depois de uma batida policial num ponto de encontro de comunistas. A Câmara dos Deputados pediu informações e o chefe de polícia informou que não havia nenhum registro de preso com aquele nome ${ }^{5}$.

Essa correspondência, mais do que fornecer indícios sobre o que poderia estar acontecendo nas ruas, nas delegacias e nos gabinetes em relação aos "suspeitos de propagandistas do crede vermelho", indica, ao longo do ano de 1934, a intensificação de tentativas de controle de algo que fora chamado de "complô" contra a "ordem e a segurança nacionais".

As transformações sociais e políticas trouxe a política institucional para o centro da discussão das classes médias e setores mais ou menos organizados dos trabalhadores e outros setores profissionais. As várias manifestações aqui descritas reuniram milhares de pessoas, tomando como parâmetro as cidades do Rio e de São Paulo. A despeito de toda rede policial, cuja diretriz era "vigiar e punir" suspeitos comunistas ou subversivos da "ordem", a sociedade civil buscava meios de defesa e, por vezes, brechas de atuação. Assim, surgiu a Comissão

\footnotetext{
3 HOBSBAWM, Eric J. Nações e nacionalismo desde 1780. Programa, mito e realidade. São Paulo: Paz e Terra, 1998

4 Correspondência entre a Câmara dos Deputados e MJNI, 10 de agosto de 1934, n.1389/34. MJNI - Série A: Segurança Pública - cx. 75 - AN.

5 Correspondência entre a Câmara dos Deputados e MJNI, setembro/1934, n.1398/34. MJNI - Série A: Segurança Pública - cx. 75 - AN.
} 
Jurídica e Popular de Inquérito (CJPI), em janeiro de $1935^{6}$, que passou a articular as ações dos deputados na Câmara Federal solicitando informações a respeito de ações policiais ao Ministério da Justiça e Negócios Interiores.

Esse grupo de oposição era composto por deputados descontentes com a crescente centralização do poder nas mãos da presidência da república, que passara a governar o país via decretos-leis ${ }^{7}$. Além dos parlamentares, participavam da comissão, entre muitos outros, Caio Prado Júnior, Aureliano Guimarães, Athos Ribeiro, Raul Cardoso de Melo Filho, Walfrido Prado Guimarães, Waldemar Rocha Barros, João Lúcio Bittencourt, Clóvis Amaral, Getúlio de Paula Santos, Paulo Marzagão, Cícero Ferreira de Abreu, Eneas Teixeira de Carvalho, José Pires, Pedro Bueno e Renato Werneck ${ }^{8}$. Parlamentares e advogados procuravam defender militantes, trabalhadores, intelectuais dos atos ilegais da polícia e acompanhar os processos jurídicos dos presos políticos.

Em janeiro de 1935, a CJPI denunciou nos tribunais atos arbitrários contra centenas de trabalhadores e intelectuais:

"[...] vítimas do terror branco que se espalha por todo o país, constatando que tais presos estão submetidos a um regime de torturas e incomunicabilidade. 0 poder judiciário, requisitando informações da polícia, está, no entanto, na impossibilidade de deferir as ordens requeridas segundo os despachos proferidos, visto que os delegados carcereiros dos presos, da ordem política e social, têm negado as inumeráveis prisões que vêm efetuando nesta capital e em todo o interior. As buscas e apreensões não têm dado resultado legal, visto que a polícia remove os presos, de um para outro lado, dificultando a ação dos advogados. [... $]^{\prime \prime}$

Cientes de que o poder judiciário poderia intervir nas ações policiais, as autoridades dos órgãos de repressão e controle políticos visavam um saneamento de ideias, buscando interceptar e dificultar a ação do judiciário, conscientes da ilegalidade de seus atos. Em meados de janeiro, 0 presidente da CJPI, em entrevista ao jornal Diário da Noite, por motivo da greve dos "chauffeurs e trabalhadores de auto-ônibus", afirmava que:

"[...] o fechamento do Sindicato dos profissionais do Volante e Anexos fere arbitrariamente todos os direitos de organização sindical entre nós, como prenuncio sombrio dos preparativos da Lei Monstro confeccionada pelo ministro Vicente Rao e seus auxiliares nesta empreitada reacionária contra o povo trabalhador do Brasil."10

A chamada "Lei Monstro" só seria aprovada em abril, mas a existência de seu projeto

Ao que parece, a CJPI citada aqui é a mesma citada por Marly Vianna, Revolucionários de 35. Sonho e realidade, São Paulo, Companhia das Letras, 1992, pp. 109 e 111. Mas no texto de Vianna aparece como Comitê Jurídico e Popular de Investigação. Infelizmente, a autora não cita suas fontes e por isso, não pudemos checar.

$7 \quad$ Em relação à crescente centralização do poder nas mãos do presidente da república ver: Pinheiro, Paulo Sérgio. Estratégias da ilusão. A revolução mundial e o Brasil: 1922-1935. São Paulo, Companhia das Letras, 1991, pp. 269-286.

8 Associação Jurídica e Popular de Inquérito, Pront. n. 262 - Deops - APESP.

$9 \quad$ Gazeta Popular, Santos, 11 de janeiro de 1935.

10 Diário da Noite, São Paulo, 16 de janeiro de 1935. 
como forma de controle legal dos dissidentes já estava em vigor e funcionando. Em dezembro de 1934, um manifesto assinado por várias organizações políticas de oposição ao governo, bem 0 demonstra:

\begin{abstract}
Ao proletariado e às massas populares de São Paulo! Trabalhadores manuais e intelectuais sem distinção de tendências políticas, credos religiosos, nacionalidade ou cor! A todos os homens de consciência livre! 0 crescimento da reação, da violência, de selvagens métodos fascistas, e de um governo que arma os integralistas [...]. No grave momento em que a polícia política metralha comícios populares; vareja e varre à bala os sindicatos operários, no Rio, Espírito Santo, em Minas, em São Paulo etc; prende, espanca, deporta e mata os que ousam ter ideias e defendê-las; como o bárbaro assassinato de Tobias Warschawsky, e a deportação de Deícola dos Santos, Augusto Besouchet, Henrique Covre, Ferreira Lima, Bernardo Chernizer, Natalino Rodrigues e tantos outros; no momento em que a camarilha dominante ataca os últimos restos das liberdades populares e incitam as provocações dos mercenários integralistas, - as organizações abaixo assinadas conclamam as massas populares e a todos os homens de consciência honesta a protestarem contra a reação e o fascismo, e a apoiarem a CJPI - Assembléia de Frente Única Popular, Liga Lombarda. Assinam: Comitê de Luta contra a Guerra Imperialista, a Reação e o Fascismo; Sindicato dos Empregados no Comércio de São Paulo; Socorro Vermelho do Brasil; União dos Alfaiates; Comitê das Mulheres Trabalhadoras; Legião Cívica 5 de julho; Federação da Juventude Comunista; Ala anti-fascista do Sindicato dos Condutores; PCB/Região de São Paulo; Oposição ao Sindicato dos Bancários; Oposição do PSB/Secção de São Paulo e Liga Comunista Internacionalista-Região de São Paulo. São Paulo, 10 de dezembro de $1934 .{ }^{11}$
\end{abstract}

As diversas organizações que assinam o manifesto, com todas as diferenças políticas e ideológicas existentes entre elas, formavam uma frente de combate para garantir alguns direitos civis e democráticos. Esse movimento era travado principalmente no campo jurídico, ao lado de outros mecanismos de mobilização da opinião pública como, por exemplo, as manifestações e comícios de rua, os manifestos e noticiários na imprensa que insistia em furar o cerco da censura.

É nesse ambiente e com lideranças desta frente que surge a Aliança Nacional Libertadora. O manifesto-programa da ANL reivindicava o cancelamento das dívidas imperialistas, a nacionalização das empresas estrangeiras, a liberdade de manifestação e o fim dos latifúndios. Os comunistas, juntamente com outros aliancistas, assumiram a defesa de um "desenvolvimento nacional" que vinha sendo barrado pela política "imperialista" de Vargas, considerada pelos aliancistas a serviço dos EUA e da Inglaterra e apoiado pelos latifundiários brasileiros. O governo Vargas, que a princípio assumira a defesa deste mesmo "desenvolvimento nacional", em 1934/1935 não havia conseguido executar o programa da Aliança Liberal. Basicamente, as propostas da ANL giravam em torno de medidas que permitissem 0 desenvolvimento econômico e de soberania nacional.

A ANL teve papel importante na aproximação de alguns intelectuais com o PCB. Nos poucos meses de legalidade da Aliança, muitos escritores e artistas se integram em suas atividades e desse grupo surge a Liga de Defesa da Cultura. Em seu manifesto, a Liga reúne vários intelectuais, muitos dos quais logo se tornam comunistas: Rubem Braga (que pertencia

11 Associação Jurídica e Popular de Inquérito, Pront. n. 262 - Deops - AESP. 
também à direção nacional da ANL), Brasil Gérson (jornalista), Acrísio Viana (advogado), Sadi Garibaldi (jornalista), Genolino Amado (advogado), Benjamin Soares Cabello (jornalista), Carlos Lacerda (estudante, que na reunião de fundação da ANL propôs Luiz Carlos Prestes - ainda em terras soviéticas - como presidente de honra da entidade sido por isso amplamente aplaudido), Maria Werneck de Castro (advogada), Anibal Machado (escritor), Aparício Torelli (jornalista), Santa Rosa (desenhista), Jorge Amado. A ANL contou ainda com grande participação de militares, antigos membros ou admiradores da Coluna Prestes, todos inspirados na memória deste combate.

Em 26 de abril, a ANL foi lançada em São Paulo e o escritor e historiador Caio Prado Júnior foi aclamado seu presidente, numa grande manifestação no Cassino do Parque Antártica $^{12}$. No início do mês, no entanto, o governo federal temendo a onda de manifestações públicas pela democracia e contra as medidas políticas de repressão e controle sociais, decidiu colocar em votação, no Congresso Nacional, a Lei de Segurança Nacional, aquela Lei Monstro à qual se referiu o presidente da CJPI, quando ainda estava em fase de elaboração pelo Ministro da Justiça, Vicente Rao'13, em janeiro de 1935.

A "Lei Monstro" foi aprovada no dia 4 de abril, pelo Congresso e com ampla maioria dos votos. À oposição parlamentar só restava protestar e continuar pressionando os chefes do governo com base no dispositivo $\S 21^{\circ}$ do artigo 113 da Constituição de 1934. Mas nada pôde barrar a ofensiva do governo contra a ANL.

Num grande comício da ANL, no Rio de Janeiro, em comemoração ao aniversário dos combates tenentistas de 5 de julho, o orador mais aclamado, Luiz Carlos Prestes, fez duras críticas ao governo, terminando com as frases: "Por um governo Popular Nacional Revolucionário! Todo poder à ANL!". Dois dias depois, Filinto Müller ordenou o fechamento do jornal A Manhã, órgão oficial da ANL, que funcionou de 24 de abril a 27 de novembro. Houve, ainda, muitas invasões policiais em sindicatos e muitos dirigentes foram presos.

$O$ discurso de Prestes foi o motivo que faltava para a grande ofensiva policial e o decreto de sua ilegalidade. 0 ambiente, no entanto, já havia sido preparado pelo jornal 0 Globo, que no dia 26 de junho publicou em suas duas edições diárias, um suposto "plano subversivo" para implantar o comunismo no Brasil14. No dia 11 de julho, foi assinado o decreto de fechamento da ANL e Filinto Müller veio a público "esclarecer" os objetivos das ações da polícia para combater o "plano de ação comunista", qualificado de "extremista" e que visava a "implantação e futura irradiação de suas doutrinas" no Brasil, como parte de um plano soviético de expansão territorial 15.

12 Relatório de 11 de junho de 1963, Setor de Arquivos e Fichários, pasta 30-k-33, doc. 174, vol. 1 - Deops AESP.

13 Vicente Paulo Francisco Rao (São Paulo, 1892-1978). Chefe de Polícia de São Paulo em 1930 e Ministro da Justiça entre 1934 e 1937.

14 O Globo, 26 de junho de 1935. 1a. e 2a. edições.

15 Entrevista de Filinto Müller, transcrita pelo Deops, 1935. Pasta 30-z-78, doc. s/n. Deops-AESP. 
Antes mesmo da fundação e do fechamento da Aliança Nacional Libertadora, em 1935, várias medidas restritivas do ponto de vista político e policial foram tomadas pelas instituições políticas e militares no Brasil: várias prisões ocorreram e muitas publicações foram censuradas (advertidas, apreendidas, proibidas e queimadas em praça pública). Filinto Müller, neste sentido, foi uma personagem bastante peculiar na história da instituição da repressão política no Brasil ${ }^{16}$. Sob sua orientação, da chefia de polícia do Distrito Federal, transmitiam-se regras e normas de conduta para a polícia de todos os Estados.

Desde o início do governo de Getúlio Vargas em 1930, as instituições policiais passaram por várias reformulações e reestruturações. Paulatinamente, colocadas em prática durante os anos trinta, uma grande reforma ocorreu em 1933. A 4 a Delegacia Auxiliar, no Rio de Janeiro, foi extinta e, em seu lugar foram criadas a Diretoria Geral de Investigações (DGI) e a Delegacia Especial de Segurança Política e Social (DESPS), posteriormente Departamento de Ordem Política e Social (DOPS).

Em sua primeira fase, a famosa $4^{\text {a }}$ Delegacia Auxiliar foi a responsável pelas investigações e pela repressão aos crimes de vadiagem, mendicância, prostituição, lenocínio, perturbação da ordem, expulsão de estrangeiros "indesejáveis", entre outras peculiaridades. Em sua estrutura, a Seção de Ordem Pública e Social tinha como objetivo a repressão às manifestações de caráter reivindicatório ou de oposição política organizadas por instituições de trabalhadores e/ou agremiações partidárias, assim como de seus dirigentes, anarquistas, comunistas ou "estrangeiros"17. Em São Paulo, desde 1924, o Departamento Estadual de Ordem Política e Social (DEOPS) tinha função análoga à SOPS.

Na fase de atuação da DESPS, já nos anos trinta, há um deslocamento de suas ações para os dissidentes políticos. De início sua organização era pequena, contando um delegado, um secretário, dois auxiliares, o chefe da Seção de Segurança Pública, o chefe da Seção de Explosivos, Armas e Munições e o chefe da Seção de Arquivo-Geral. As verbas e os investigadores ficavam a critério do chefe de polícia; portanto, o funcionamento da delegacia não estava preso a critérios previamente estabelecidos, mas funcionava de acordo com os interesses políticos do momento ${ }^{18}$.

16 Há um trabalho bem interessante sobre a trajetória de Filinto Müller, cujo enfoque recaí nas relações políticas baseadas nas trocas de favores entre personalidades e o chefe da policia do DF, assim como problematiza a constituição do arquivo de correspondência de Müller, depositado na Fundação Getúlio Vargas-RJ: Luciana Quillet Heymann, As obrigações do poder: relações pessoais e vida publica na correspondência de Filinto Müller, Dissertação de Mestrado, Museu Nacional/UFRJ, 1997.

17 Para as ações da 4a. Delegacia Auxiliar, ver: Bretas, op. cit.; __, A guerra das ruas: povo e polícia na cidade do Rio de Janeiro, Rio de Janeiro, Arquivo Nacional, 1997; Paulo Sérgio Pinheiro e Michael M. Hall, A classe operária no Brasil, São Paulo, 1979, vol. 1; P. S. Pinheiro, Estratégias da ilusão, op. cit., capítulo 15. A "terceira revolução" (de Getúlio Vargas); Olívia Maria Gomes da Cunha, Intenção e gesto: política de identificação e repressão à vadiagem no Rio de Janeiro nos anos 30, Rio de Janeiro, Tese de Doutorado apresentada ao Departamento de Antropologia Social-Museu Nacional, 1998.

18 Em que pese a inexistência de um amplo estudo sobre a policia política: as origens, o funcionamento, seus órgãos administrativos e de ação, assim como seus projetos e suas políticas, há alguns estudos que fornecem pistas importantes para a pesquisa desse tema. Sobre a polícia no governo Vargas, ver: Elizabeth Cancelli, 0 mundo da violência. A polícia da era Vargas. Brasília, Editora da Universidade de Brasília, 1993. Especificamente 
Faltava apenas uma legislação que legitimasse as ações da polícia política, um instrumento que adequasse a estrutura repressiva criada aos objetivos do Governo Vargas. 0 Código Penal de 1890, feito logo após a Proclamação da República, e a Constituição de 1934, ainda traziam empecilhos a esse tipo de intervenção das forças policiais. Nesse sentido, em 4 de abril de 1935, foi colocada em vigor a conhecida "Lei Monstro" (Lei n. 38 - Define crimes contra a ordem política e social).

Alguns aspectos desta lei são fundamentais para entender o processo repressivo que se instaura após os levantes militares e civis de novembro de 1935. Em seu capítulo III, a referida lei, define a "ordem política" e a "ordem social":

$\S 1^{\circ} \mathrm{A}$ ordem política, a que se refere este artigo, é a que resulta da independência, soberania e integridade territorial da União, bem como da organização e atividade dos poderes políticos, estabelecidas na Constituição da República, nas dos Estados e nas leis orgânicas respectivas.

$\S 2^{\circ} \mathrm{A}$ ordem social é a estabelecida pela Constituição e pelas leis relativamente aos direitos e garantias individuais e sua proteção civil e penal: ao regime jurídico da propriedade, da família e do trabalho; à organização e funcionamento dos serviços públicos e de utilidade geral; aos direitos e deveres das pessoas de direito público para com os indivíduos e reciprocamente. ${ }^{19}$

Portanto, os crimes contra a ordem política e social também são limitados e se materializam em "tentar, diretamente e por fato, mudar, por meios violentos, a Constituição da República, no todo ou em parte, ou a forma de governo por ela estabelecida", "incitar diretamente o ódio entre as classes sociais", "instigar as classes sociais à luta pela violência", "instigar desobediência coletiva ao cumprimento de lei de ordem pública", ou ainda promover "qualquer distúrbio nos meios militares". O delito é inafiançável e o acusado culpado poderia ficar preso entre 1 a 10 anos.

Assim, a circulação impressa de ideias da "doutrina comunista" passou a ser crime:

Art. 25. Quando os crimes definidos nesta lei forem praticados por meio da imprensa, proceder-se-á, sem prejuízo da ação penal competente, à apreensão das respectivas edições. A ação desta medida competirá, no DF, ao Chefe de Polícia, e nos Estados e no Território do Acre, à autoridade policial de maior graduação no lugar. [...]

Art. 26. É vedado imprimir, expor à venda, vender, ou, de qualquer forma, por em circulação gravuras, livros, panfletos, boletins ou quaisquer publicações não periódicas, nacionais ou estrangeiras, em que se verifique a prática de ato definido como crime nesta lei, devendo-se apreender os exemplares sem prejuízo da ação penal competente. ${ }^{20}$

A "Lei Monstro" ainda previa a proibição de partidos, centros, agremiações ou sindicatos que visassem "a subversão, pela ameaça ou violência da ordem política e social", assim como quaisquer de seus participantes ou membros seriam penalizados nas formas previstas da lei. $\mathrm{A}$

sobre a história e as possibilidades dos arquivos das delegacias e/ou departamentos de ordem Política e Social, ver: Beatriz Kushnir, "Pelo buraco da fechadura - O acesso à informação e as fontes: os arquivos do DOPS (RJ e SP)", in: Maria Luiza Tucci Carneiro (org.). Minorias Silenciadas: história da censura no Brasil. São Paulo, Edusp, 2002. pp.553-585; Antonio Luigi Negro e Alexandre Fortes, "Direita e esquerda. Fontes nacionais para a história social", mineo.; e Paulo Fontes, "Trabalhadores em São Paulo: ainda um caso de policia", mineo.

19 Lei $n^{0} 38$ - de 4 de abril de 1935, Coleção de Leis do Brasil - Actos do Poder Legislativo, ano 1935, p

38.

20 Idem, ibidem, p. 39. 
lei estabelecia também que funcionários públicos e professores universitários que fossem processados e julgados culpados perderiam imediatamente 0 cargo.

Assim, organismos de repressão criados e leis que permitissem sua ação, a liberdade de credo político ou de crítica passa a ser um "caso de polícia". Mas, como veremos, ainda havia brechas e entre o que se prescrevia na lei e a ação policial havia um grande abismo.

Quando a "Lei Monstro", apesar de sua amplitude, não conseguiu abarcar os interesses políticos de grupos do governo, ela foi deixada de lado e passou, em novembro de 1935, a vigorar o "estado de sítio". Essa politização da ação policial teve suas razões:

A repressão política 'politiza' (perdoada a redundância) a luta contra o crime,
transformando todos os vadios em 'ladrões, assaltantes e arrombadores',
prostitutas, menores nocivos, revolucionários em potencial e criminosos
'políticos', capazes de serem utilizados pelos agitadores. Na ação policial, o
regime de exceção unifica a luta contra o crime comum e o crime político,
com a diferença de que, no caso do primeiro, o exame judicial continua nulo,
ao passo que para o segundo o procedimento jurídico requer mais
sofisticação ${ }^{21}$

A trajetória de Dionélio Machado, gaúcho, médico e escritor é bastante elucidativa das práticas policiais cometidas em nome da lei. Quando se formou a Aliança Nacional Libertadora em Porto Alegre, em agosto de 1935, sendo o seu presidente estadual, o escritor fora preso em consequência da Lei $n^{0} 38$ e autuado nos artigos 25,26 e 30. Da prisão enviou um artigo para 0 jornal A Manhã, órgão oficial da ANL e afirmou:

[...] a Aliança operou entre nós o despertar da consciência popular revolucionária no Estado - verdadeiro milagre, tendo-se em conta o espírito da nossa gente, que passa toda sua existência de povo politicamente organizado a transitar das mãos de uns caudilhos para as de outros, anulada em suas vontades, enganada por uma demagogia desenfreada [...]. ${ }^{22}$

Dionélio Machado enxergou a ANL como um momento peculiar na história dos movimentos sociais no Brasil, não deixando de notar a qualidade de "inocente útil" da "nossa gente". Pouco antes, Dionélio havia enviado os manuscritos de seu romance Os ratos, à Companhia Editora Nacional, propriedade de Othales Marcondes Ferreira e localizada em São Paulo. A editora estava organizando o concurso literário "Prêmio Machado de Assis", no qual o vencedor teria seu romance publicado pela casa. No júri, os escritores Gastão Cruls, Monteiro Lobato, Gilberto Amado, Agripino Grieco e, representando a editora, Moacyr Deabreu não escondiam o favoritismo pelos romances de Marques Rebelo, de João Alphonsus e Érico Veríssimo.

Jorge Amado era um assíduo frequentador dos bastidores da editora e muito amigo de Veríssimo; de posse de tal informação, foi avisar o amigo das preferências do júri. Entretanto, Érico Veríssimo pediu-lhe que interviesse junto ao júri em favor de um amigo que se encontrava

21 Paulo Sérgio Pinheiro, Estratégias da llusão..., op. cit., p. 112.

22 A Manhã, 17 de outubro de 1935, p. 3. 
preso acusado de ser comunista, Dionélio Machado. Jorge Amado realizou o pedido de Érico e foram premiados pela editora: Dionélio Machado, Érico Veríssimo, Marques Rebelo e João Alphonsus ${ }^{23}$.

Um escritor e preso político que, nessas condições, ganhava um prêmio literário e a publicação de um romance de sua autoria dentro do pequeno quadro de grandes editoras de âmbito nacional, ganhava certa "imunidade política" e se integrava numa, ainda que frágil, rede de solidariedade intelectual.

Mas, sob o pretexto de prender os responsáveis pelos levantes liderados por Prestes, em novembro de 1935, a polícia de todo o país iniciou uma onda de prisões talvez jamais vista em nossa história. Entre militares e civis, milhares de pessoas foram detidas para "averiguação e suspeitas de envolvimento com a intentona comunista", muitas delas saindo da prisão anos mais tarde. Essa virulência atingiu em cheio também setores intelectualizados da oposição.

Dois dias antes da deflagração dos levantes, o jornal Diário da Noite publicou um manifesto intitulado: "Frente Popular pela liberdade". O manifesto é a denúncia das precárias condições econômicas e sociais da grande maioria da população brasileira, a miséria que se alastra pelo campo e a falta de alimentação nos lares dos trabalhadores. Reafirmou o valor da tradição brasileira nas lutas por justiça e liberdade social, como a insurreição do Forte de Copacabana, em 1922 e o levante em São Paulo. Herdeira natural dessas lutas, a Aliança Liberal tinha em seu programa reivindicações populares e trabalhistas vindas das lutas dos anos vinte.

Segundo ainda o manifesto, pouco depois que um grupo da Aliança Liberal chegou ao governo, traiu o programa popular e bandeou-se para o lado dos "adecistas de décima hora". Segundo o manifesto, o programa liberal foi jogado no lixo. Promulgou-se a Constituição e logo após criou-se a Lei de Segurança Nacional para privar qualquer cidadão do livre exercício democrático. Teve, então, início a "fascistização" do Brasil, através da qual toda e qualquer manifestação reivindicatória poderia ser suspensa ou proibida e qualquer um de seus participantes poderia ser preso. Não bastassem tais abusos, continua o manifesto, o governo federal iniciou a intervenção nos Estados, cujo objetivo era o controle total do poder no país, sem riscos de manifestações de oposição.

Entre os militares, políticos e intelectuais que assinaram o manifesto estavam gal. Miguel Costa, cel. Colombo de Mello Matos, Danton Vampré, Caio Prado Júnior, José Maria Gomes, Waldemar Rangel Belfort e Matos, Isaltino Veiga dos Santos²4. No dia seguinte à publicação, a Delegacia de Ordem Política de São Paulo, instaurou inquérito contra o escritor e militante, Caio Prado Júnior. Procurado por policiais em sua residência em São Paulo, Caio Prado não foi encontrado, sendo informados por um empregado da casa que o mesmo se encontrava no Rio

23 Jorge Amado, Navegação de Cabotagem, Rio de Janeiro, Editora Record, 1992, pp. 515 a 517 . Érico Veríssimo, Solo de Clarineta, Porto Alegre, Editora Globo, 1974, vol. I, pp. 259 e 260.

24 "Manifesto da Frente Popular pela Liberdade", Diário da Noite, São Paulo, 23 de novembro de 1935. 
Grande do Sul. A Delegacia enviou telegrama à polícia da capital gaúcha pedindo informações sobre o seu paradeiro. No dia 26 , a polícia e as forças armadas do país já estava de prontidão à espera das rebeliões que poderiam ocorrer nos quartéis, aos moldes dos acontecimentos de Natal, onde alguns militares rebelados e comunistas formaram uma junta de governo que, no entanto, fora rapidamente derrotada pelas forças fiéis a Getúlio Vargas.

A polícia gaúcha de prontidão respondeu informando que Prado Júnior havia visitado 0 escritor Dionélio Machado, que era "acusado de fortes suspeitas de ligação com movimento no Norte do país" e que havia sido posto em liberdade há pouco tempo25. Imediatamente, a polícia paulistana solicitou a prisão de Caio Prado em Porto Alegre. Na manhã do dia 27 de novembro, policiais chegaram ao Novo Hotel Jung, onde Caio Prado havia se hospedado. Solicitaram a presença do acusado que, ao se apresentar aos policiais, foi detido e levado à Delegacia de Ordem Social. Caio Prado foi registrado como advogado e em seu depoimento afirmou ter sido presidente da ANL-SP e que havia viajado até Porto Alegre para visitar a Exposição Farroupilha e o Instituto Histórico e Geográfico local. Por recomendação do Major Lousada, o escritor paulistano disse ainda, conheceu o professor Tupy Caldas, o qual the acompanhou em várias visitas feitas na capital do Estado26. Quanto ao seu encontro com Dionélio Machado, Caio Prado informou à polícia que, apesar não o conhecer pessoalmente, foi visitá-lo e que conversaram sobre diversos assuntos, inclusive sobre política27.

Após o depoimento, o escritor foi detido no $1^{\circ}$ Batalhão da Infantaria da Brigada Militar. Muito provavelmente por conhecer o Major Lousada e por sua intervenção, dois dias depois Caio Prado foi libertado. Em seu depoimento, o Major Lousada afirmou "ter tido a melhor das impressões sobre o dr. Caio Prado"28. Caio Prado retornou no mesmo dia para São Paulo e, alguns dias depois, Dionélio Machado fora detido para prestar depoimentos sobre seu encontro com Caio Prado, tendo então afirmado não ter tido nenhuma conversa sobre assuntos políticos e que acabara de conhecê-lo, tratando unicamente de assuntos gerais. Machado foi liberado algumas horas depois do depoimento 29 .

$O$ delegado da DOS pediu então a abertura de processo contra Caio Prado baseado nos artigos 1, 4, 19 e 20, da Lei $n^{0} 38$. 0 inquérito foi instaurado e continuaram as investigações. Ao desembarcar em Santos, Caio Prado Júnior foi detido e levado à Superintendência de Ordem Política e Social de São Paulo, onde prestou um novo depoimento, no qual repetiu o que havia dito à polícia em Porto Alegre e acrescentou várias vezes não ter conhecimento dos planos da

25 Chefia de Polícia-Porto Alegre à Chefia de Polícia-São Paulo, Telegrama, s/d, fls. 26. Processo nº 237-a / Apelação $n^{\circ} 226$ - Caio Prado Júnior - Tribunal de Segurança Nacional - Arquivo Nacional.

26 O Major Manuel Lousada era oficial da Brigada Militar-RS. Homem de grande consideração de Getúlio Vargas no Rio Grande do Sul, já que Ihe informava sobre as articulações políticas de Flores da Cunha, governador do estado, contra seu governo. Cf. Getúlio Vargas, Diário, Rio de Janeiro, Editora Siciliano/FGV, 1995, pp. 437, 449 e 455 .

27 Caio Prado Júnior, Termo de Declarações à DOS-RS, 27 de novembro de 1935, fl. 132. Processo n² 237, cit., idem, ibidem.

28 Major Manoel Lousada, Depoimento à DOS-RS, fl. 133. Processo n 237, idem, ibidem.

29 Dionélio Machado, Depoimento à DOS-RS, fl. 133. Idem, ibidem. 
rebelião em Natal, Recife e Rio de Janeiro, no fim de novembro de 1935, afirmando só ter tomado conhecimento dos fatos pelos jornais.

O que se segue dai tanto na trajetória de Dionélio Machado quanto na de Caio Prado Júnior é uma outra história. Mas o que se percebe é que a atividade intelectual "suspeita", comunista ou não, era necessariamente determinada pelo capital cultural e social que esses escritores haviam acumulado. Prestígio profissional e origem social faziam a diferença na hora de lidar com as instituições repressivas e de censura.

Caio Prado Júnior nascera em uma família tradicional da aristocracia cafeeira de São Paulo, bacharel formado pela Faculdade de Direito do Largo S. Francisco e ex-militante do Partido Democrático. Já havia publicado, no início dos anos trinta, pela Editora Martins, o livro Evolução Política do Brasil e outros estudos. Ensaio de interpretação materialista da História do Brasil, e ainda teve livre trânsito para publicar um livro de propaganda e divulgação sobre a União Soviética. Dionélio Machado não contava com as mesmas condições de seu colega paulistano e a rede de intelectuais construída na órbita das grandes editoras teve que ser mobilizada para garantir a integridade física do escritor gaúcho.

Assim, ser um escritor "consagrado" ou cuja atividade profissional estava ligada ao poder de "dizer das coisas" não significava necessariamente cooptação ou colaboração, pode ter significado apenas o encontro de possibilidades de sobrevivência como escritor profissional em uma situação de criminalização da política e de instrumentalização da polícia para esses fins.

\section{Bibliografia:}

1. AMADO, Jorge. NBibliografia:avegação de Cabotagem, Rio de Janeiro, Editora Record, 1992.

2. BRETAS, Marcos. A guerra das ruas: povo e polícia na cidade do Rio de Janeiro, Rio de Janeiro, Arquivo Nacional, 1997.

3. CANCELLI, Elizabeth. 0 mundo da violência. A polícia da era Vargas. Brasília, Editora da Universidade de Brasília, 1993.

4. CUNHA, Olívia Maria Gomes da. Intenção e gesto: política de identificação e repressão à vadiagem no Rio de Janeiro nos anos 30, Rio de Janeiro, Tese de Doutorado apresentada ao Departamento de Antropologia Social-Museu Nacional, 1998.

5. DAGNINO, Evelina. "Cultura, cidadania e democracia. A transformação dos discursos e práticas na esquerda latino-americana", in: (org.), Cultura e política nos movimentos sociais latino-americanos. Novas leituras. Belo Horizonte, Editora UFMG, 2000, pp. 61-102.

6. DURHAM, Eunice Ribeiro. "Movimentos Sociais. A construção da cidadania", in: Novos Estudos Cebrap, São Paulo, outubro/1984, n. 10, pp. 24-30.

7. FORTES, Alexandre \& NEGRO, Antônio Luigi. Esquerda e direita: fontes nacionais para a História social. Métis: história \& cultura. Vol. 3, no 5, janeiro/junho de 2004.

8. HEYMANN, Luciana Quillet. As obrigações do poder: relações pessoais e vida publica na correspondência de Filinto Müller, Dissertação de Mestrado, Museu Nacional/UFRJ, 1997.

9. HOBSBAWM, Eric J. Nações e nacionalismo desde 1780. Programa, mito e realidade. São Paulo: Paz e Terra, 1998.

10. KUSHNIR, Beatriz. "Pelo buraco da fechadura - 0 acesso à informação e as fontes: os arquivos do DOPS (RJ e SP)", in: CARNEIRO, Maria Luiza Tucci (org.). Minorias Silenciadas: história da censura no Brasil. São Paulo, Edusp, 2002.

11. PINHEIRO, Paulo Sérgio. Estratégias da ilusão. A revolução mundial e o Brasil: 19221935. São Paulo, Companhia das Letras, 1991. 
12. PINHEIRO, Paulo Sérgio e HALL, Michael M. A classe operária no Brasil, São Paulo, 1979.

13. VARGAS, Getúlio. Diário, Rio de Janeiro, Editora Siciliano/FGV, 1995.

14. VERÍSSIMO, Érico. Solo de Clarineta, Porto Alegre, Editora Globo, 1974.

15. VIANNA, Marly. Revolucionários de 35 . Sonho e realidade, São Paulo, Companhia das Letras, 1992.

\section{Documentos}

1. Associação Jurídica e Popular de Inquérito, Pront. n. 262 - Deops - Arquivo Público do Estado de São Paulo.

2. Caio Prado Júnior, Termo de Declarações à DOS-RS, 27 de novembro de 1935, fl. 132. Processo $n^{0} 237$ - Tribunal de Segurança Nacional - Arquivo Nacional.

3. Chefia de Polícia-Porto Alegre à Chefia de Polícia-São Paulo, Telegrama, s/d, fls. 26. Processo $n^{\circ}$ 237-a / Apelação $n^{\circ} 226$ - Caio Prado Júnior - Tribunal de Segurança Nacional - Arquivo Nacional.

4. Correspondência entre a Câmara dos Deputados e MJNI, 10 de agosto de 1934, n.1389/34. MJNI - Série A: Segurança Pública - cx. 75 - AN.

5. Correspondência entre a Câmara dos Deputados e MJNI, setembro/1934, n.1398/34. MJNI Série A: Segurança Pública - cx. 75 - AN.

6. Dionélio Machado, Depoimento à DOS-RS, fl. 133. TSN/AN.

7. Entrevista de Filinto Müller, transcrita pelo Deops, 1935. Pasta 30-z-78, doc. s/n. Deops-AESP.

8. Lei no 38 - de 4 de abril de 1935, Coleção de Leis do Brasil - Actos do Poder Legislativo, 1935.

9. Major Manoel Lousada, Depoimento à DOS-RS, fl. 133. Processo no 237 - TSN/AN.

10. "Manifesto da Frente Popular pela Liberdade", Diário da Noite, São Paulo, 23 de novembro de 1935.

11. Relatório Policial sobre a Conferência Anti-Integralista, 15 de novembro de 1933. Pront. n. 37 Aristides Lobo, DEOPS-SP, AESP.

12. Relatório de 11 de junho de 1963, Setor de Arquivos e Fichários, pasta 30-k-33, doc. 174, vol. 1 - Deops - AESP.

\section{Periódicos}

1. A Manhã, 17 de outubro de 1935, p. 3.

2. Diário da Noite, São Paulo, 16 de janeiro de 1935.

3. Gazeta Popular, Santos, 11 de janeiro de 1935.

4. 0 Globo, 26 de junho de 1935. 1a. e 2a. Edições.

Artigo recebido em: 02/06/2011

Aprovado em: 21/06/2011 